\title{
Transcriptome and Coronavirus: New Hope and Therapy
}

\author{
Khaled Mohamed Mohamed Koriem ${ }^{1, *(D)}$ \\ 1 Department of Medical Physiology, Medical Research Division, National Research Centre, 33 El-Buhouth Street, Dokki, \\ Cairo, 12622, Egypt \\ * Correspondence: kkoriem@yahoo.com;
}

Scopus Author ID 24477156100

Received: 20.08.2020; Revised: 7.09.2020; Accepted: 9.09.2020; Published: 13.09.2020

\begin{abstract}
Transcriptome refers to all RNA particles occur inside one cell or inside numerous cells in one organ. Coronaviruses are a family of correlated viruses that induce viral infection. In humans, coronaviruses induce respiratory viral infections that may be mild or dangerous. The coronavirus shape is large circular elements that have round tip outbreaks - the virus diameter particles $=120 \mathrm{~nm}$. The RNA viral genome occurs in coronavirus. The coronavirus genome size $=27-34$ kilobases, and this size is the largest RNA genome size. The Life cycle of coronavirus includes viral entry, replication, and release. Coronavirus transmission was done through the connection of its protein with host cell receptors in a specific process. There are 4 types of coronavirus genus: (1) Alphacoronavirus, (2) Betacoronavirus, (3) Gammacoronavirus, and (4) Deltacoronavirus. Viral replication, immune evasion, and virion biogenesis correlated with host cell transformation mechanism. Viral molecular mechanism hijacks the host cell protein production mechanism. There is an important host factor (CPSF6) that connects with nuclear protein (NP1). The CPSF6 increases the nuclear production of NP1 in the same time, CPSF6 possesses an important role in the progress of capsid mRNAs inside the nucleus. In a viral infection, there is an increase in mRNA, myeloid differentiation 2-related lipid recognition protein (ML), and Niemann Pick-type C1 (NPC1) genes. Coronavirus is capable of replicating in in vitro study and causes lower transcriptomic variations before $12 \mathrm{~h}$ after viral infection. As infection progress, coronavirus causes a significant dysregulation of the host transcriptome greater than the SARS virus. In conclusion, future transcriptome studies are the basis for detecting coronavirus in the human host and for developing a specific preventive and therapeutic method for the virus.
\end{abstract}

Keywords: Transcriptome; Coronavirus; Life cycle; Genome; Transmission.

(C) 2020 by the authors. This article is an open-access article distributed under the terms and conditions of the Creative Commons Attribution (CC BY) license (https://creativecommons.org/licenses/by/4.0/).

\section{Introduction}

The term transcriptome refers to all RNA particles occur inside one cell or inside numerous cells in one organ. This term sometimes includes all RNAs, or maybe only mentioned to mRNA. Transcriptome term could be identified from the exome term, where transcriptome refers to RNA particles inside one cell, but usually, this term contains all RNA particles besides their molecular characterization. Application of 2 complementary methods, a high-resolution map of the betacoronavirus of COVID-19 transcriptome discovered where at least 41 RNA modification sites on viral transcripts were reported [1]. Transcriptome term varies from translatome term, where translatome refers to all RNAs translation inside the cell. There is a tight correlation between lipidomic, metabolomic, and proteomic, especially in protective and therapeutic studies [2-4]. Transcriptome term refers to all transcription processes inside one organ (liver, kidney, testis, ovary, spleen, or pancreas), or this term include a series of transcription processes that occur in one cell. Transcriptome varies from genome where https://biointerfaceresearch.com/ 
transcriptome differs according to outside environmental circumstances. Transcriptome includes all transcripts processes of mRNA inside the cell, so transcriptome includes gene expression indie the cell, but this terminology does not include mRNA breakdown, e.g., transcriptional decrease. Transcriptome contains expression process, and RNA molecular analysis studies the expression process of RNAs inside many cells, and usually refers to mRNA, tRNAs, and sRNAs. Transcriptomics method techniques contain DNA microarrays and next-generation method tools (Sequencing method). Transcriptomics includes all researches focus on gene transcriptions.

Transcriptome contains two principal methods: (1) One genes map arrangement focuses on a specific genome inside the specific organism or defined specific species. (2) The other approach, the de novo transcriptome method, where new technology is applied to a specific gene transcript arrangement. The most interesting and obvious transcriptome method contains stem cells and cancer cells, where the researchers could clearly understand the processes of cellular behavioral and tumor processes. Transcriptome focus on the human testis, ovary, and fetuses applied to explores the molecular process and genes signaling processes involve in initial fetuses' growth, and this process helps the researcher to obtain fetuses free of genetic defects [5]. Transcriptomics is more specific in biomarkers discovery to determine the drug's safety and chemical toxicity detection [6]. Finally, transcriptomes are applied to investigate genetic similarity inside humans or communities. The gene expression depends on the wide bridge between transcription and RNA processing, where the changes in RNA regulation provide important ideas for modeling cell-specific transcriptome [7]. Coronaviruses are a family of correlated viruses that induce viral infection in mammals and avian. In humans, coronaviruses induce respiratory viral infections that may be mild (common cold symptoms, e.g., rhinoviruses species of coronaviruses) or maybe dangerous (e.g., COVID-19 besides MERS and SARS). The coronaviruses signs in chickens (induce superior breathing system disease) but in cows and pigs (induce diarrhea). Until now, there are no antiviral vaccines or therapeutic agents to avoid or tolerate human coronavirus. The coronaviruses usually infect the upper or lower respiratory tract; viral spreading in plasma or serum is common. In COVID-19 cases, the attention of blood safety is recommended where coronaviruses have globally arisen, especially in endemic areas [8]. The taxonomy of coronaviruses contains family (Coronaviridae), subfamily (Orthocoronavirinae), order (Nidovirales), and realm (Riboviria) $[9,10]$. Coronaviruses consist of single-stranded RNA with specific genetic arrangements covered by an enveloped viral cover - the RNA strand size of coronaviruses $=27-34$ kilobases [11]. The coronavirus derived their names from the name Latin corona (refers to "crown" or "halo" due to the specific shape of a significant solar corona around the virions (virus strands) through two-dimensional transmission electron microscopy application.

\section{Coronavirus history}

Starting in 1930, coronaviruses first appeared where an avian respiratory disease called IBV was the first diagnostic then in 1940; coronaviruses infected another two animal models: (1) MHV (in mice) and (2) TGEV (in the digestive system) were diagnostic [12]. The first human case of coronaviruses reported in Chinese common cold patients and later on called human coronavirus 229E and human coronavirus OC43 [13] then other Chinese human cases 
of coronaviruses were diagnostic in 2003, then another cases in 2004, 2005, 2012, and 2019 where the majority of all the above-mentioned cases include severe respiratory cases.

Regarding human infections, coronaviruses were first discovered in 1960 [11]. In 2019, a new coronavirus (nCoV) was named SARS-CoV-2, while the disease is named COVID-19. More than 1800 Chinese people were dead due to this virus, commonly elderly or those with chronic or immune-problem diseases. This is $3^{\text {rd }}$ serious coronavirus outbreak during the last 20 years, after SARS in 2002-2003 and MERS in 2012 [14]. There are 7 coronaviruses induce human infections (4 of which, HCoV 229E, HCoV NL63, HCoV HKU1, and HCoV OC43 cause cold symptoms in humans while the other 3 coronaviruses called SARS-CoV (severe acute respiratory syndrome coronavirus), MERS-CoV (Middle East respiratory syndrome coronavirus) and COVID-19 cause severe respiratory illness [15].

\section{Coronavirus terminology}

Coronavirus is derived its name from the Latin corona word. This means crown or wreath. The source of the virus name obtained from the Greek word "корต́vๆ korônē". This name mentions to the specific shape of virions (the most infectious part of this virus) via electron microscope, where a crown or of a solar corona appeared under this microscope. This virus shape is produced by the viral spike peplomers, which are proteins that accumulate on the surface of the virus [16].

\section{Coronavirus morphology}

The coronavirus shape is large circular elements that have round tip outbreaks [17]. The virus diameter $=120 \mathrm{~nm}$ [18]. The virus has an envelope with an electron micrograph, which is observed as a separate pair of dense shells [19]. Coronavirus envelops consists of two lipid layer covers one protein layer inside where the membrane $(\mathrm{M})$, envelope $(\mathrm{E})$, and spike $(\mathrm{S})$ proteins are arranged [20] in the coronavirus. Betacoronavirus, which represents one type of coronaviruses, possesses an additional surface protein [9]. The nucleocapsid (contains several types of nucleocapsid (N) protein) occurs inside the virus envelope. This protein forms a strong bond with the viral RNA genome $[18,21]$. The two lipid layers and the protein layer of the virus envelop, as well as, nucleocapsid protein protects coronavirus outside the host cell in the fresh air [22].

\section{Coronavirus genome}

The RNA viral genome occurs in coronavirus. The coronavirus genome size $=27-34$ kilobases [23], and this size can be considered as the largest RNA genome size. The viral genome possesses the top strand ( $5^{\prime}$ methylated top) and bottom ( $3^{\prime}$ polyadenylated bottom) [18]. The RNA genome arrangement is top-UTR-spike-envelop-membrane-nucleocapsidepoly (A) bottom. The RNA frame 1a and $1 \mathrm{~b}$ occurs in the top 2/3 of RNA genome encrypts the replicase/transcriptase polyprotein. The replicase/transcriptase polyprotein self-breaks inside the host cell to form nonstructural proteins [18]. The remaining 1/3 of the viral RNA genome contains the 4 principal proteins: spike, envelope, membrane, and nucleocapsid [24]. The accessory proteins represent the connection bridge among the above mentioned 4 principal viral proteins. These accessory proteins possess different functions and numbers depending on the environmental condition of the coronavirus [18]. 


\section{Life cycle of coronavirus}

\subsection{Viral entry.}

The coronavirus infection process starts as soon as the viral spike (S) glycoprotein connects to the cell receptors of the host. Following that, the host cell protease breaks and activates at the same time, the spike protein occurs in the viral receptor, according to the number and activation of the host cell protease, a breakdown, and activation of the coronavirus to invade the host cell through endocytosis (direct connection of viral envelop with host cell membrane) [25]. As soon as the coronavirus invades the host cell, the viral envelop breaks and viral RNA genome swimming in the host cell cytoplasm [18]. As mentioned before, the viral RNA genome possesses top and bottom, and this specific viral structure enables viral RNA to connect with host cell ribosomes to accelerate RNA genome transcription [18]. The host cell ribosome accelerates the process of viral RNA production to form a long polyprotein viral chain. This polyprotein viral chain possesses its specific proteases, which break the long-chain viral polyprotein into small and specific proteins [18].

\subsection{Viral replication.}

There are many of small protein particles unites together to form a large replicasetranscriptase complex (RTC) protein molecule. This large protein molecule is the RNAdependent RNA polymerase (RdRp). This large protein molecule incorporates in replication and transcription of RNA from a single strand RNA of coronavirus. There are small protein molecules promoting the replication and transcription of viral RNA, and these protein molecules are called exoribonuclease protein. This exo-ribonuclease protein helps the replication of viral RNA by the formation of RNA polymerase lacks [26] complex protein, which replicates the viral RNA genome. The RdRp molecule promotes the production of a negative-sense RNA genome from the positive-sense RNA genome, where the replication of the positive-sense RNA genome from the negative-sense RNA genome [18] occurs. The RdRp promotes the production of negative-sense RNA genome molecules from the positive-sense RNA genome where transcription of negative-sense RNA subgenome molecule to positivesense mRNAs [18] of coronavirus.

\subsection{Viral release.}

The resulting positive-sense RNA genome from viral replication represents the new generation coronavirus. The mRNAs are produced from the transcription of the lower part of the viral genome after the replication of the upper $2 / 3$ of the viral RNA genome. The resulting mRNAs are covered by the host ribosomes to various larger proteins and few and small accessory proteins [18]. This process of transformation of mRNAs happens inside the endoplasmic reticulum of the host. The resulting 3 viral proteins molecules (spike, envelop, and membrane) transport through the secretory pathway into the Golgi middle partition. In the Golgi compartment, the membrane proteins control all protein-protein connections to meet coronavirus after a virus connection with the nucleocapsid [27] of the host. The new generation coronaviruses are finally emerged in the host cell through secretory vesicles by a process called virus exocytosis [27]. 


\section{Coronavirus transmission}

There is a specific process that connects its protein with the host cell receptors i.e., and each coronavirus connect with a specific receptor in each viral infection occurs [28, 29]. As an example, the SARS coronavirus connects to human cells through assigning to a specific receptor [30].

\section{Coronavirus taxonomy}

The Orthocoronavirinae or Coronavirinae refers to the coronavirus scientific name [31-33] while coronavirus under the family of Coronaviridae. There are 4 types of coronavirus genus: (1) Alphacoronavirus, (2) Betacoronavirus, (3) Gammacoronavirus, and (4) Deltacoronavirus. Each virus genus contains different species as follows; (1) Genus: Alphacoronavirus includes the following species; Human coronavirus (229E and NL63), Miniopterus bat coronavirus (1 and HKU8), Porcine epidemic diarrhea virus, Rhinolophus bat coronavirus HKU2, Scotophilus bat coronavirus 512. (2) Genus Betacoronavirus includes Murine coronavirus; Betacoronavirus 1 (Human coronavirus OC43), Human coronavirus HKU1, Murine coronavirus, Tylonycteris bat coronavirus HKU4, MERS, Pipistrellus bat coronavirus HKU5, Rousettus bat coronavirus HKU9, SARS-CoV, SARS-CoV-2, Hedgehog coronavirus 1 (EriCoV). (3) Genus Gammacoronavirus includes Infectious bronchitis virus; White whale coronavirus SW1, Infectious bronchitis virus. (4) Genus Deltacoronavirus includes Bulbul coronavirus HKU11, Pig coronavirus HKU15.

\section{Transcriptome view of viral replication cycles}

The viral replication, immune evasion, and virion biogenesis correlated with the host cell transformation mechanism. The viral molecular mechanism hijacks the host cell protein production mechanism. The virus is attached to the endoplasmic reticulum (ER) where the viral life cycle, replication, and mechanism are largely regulated by the ER [34]. The suitable and most related method to study viral cellular and RNA genome is a single-cell sequencing (SCS) application. This technique enables researchers and scientists to explore viral, cellular genome, and transcriptome. This application gives more details on viral infection mechanisms at a single-cell level. The viral life cycle changes according to viral sequences and viral-host transcriptome investigations [35]. The viral transcriptome examination shows the difference of host reactions according to virus infection in groups of permissive cells. These differences occur at the gene level, and these observations help in the application of a specific permissive culture system to investigate the murine norovirus immunity, pathogenesis, and drug progress [36]. The synthetic viral transcription factor Zta binding site converses Zta at the distance binding site, and consequently, affects viral cellular genes arrangement, and this leads to conclude that viral transcription factor Zta rearrangements the RNA appearance [37].

The next-generation sequencing technique applies to detect genetic changes in cellular microRNAs in HIV-infected cells. This technique is very accurate, and consequently, the genetic microRNAs changes detect early in viral infection, i.e., earlier to viral replication. In the early viral infection, microRNAs are expressed, but at HIV-infection, late-stage microRNAs become overexpressed, and viral symptoms appear. The next-generation sequencing technique identifies the role of microRNAs in transcriptional rule in HIV infection, and the number of microRNAs occurs in the expression of HIV cofactor [38]. The collecting 
of single cells emerges from viral expression helping in the rearrangement of the viral transcriptional path. Rearrangement cells emerge from this path gives rise to viral genetic programs composed of genes with a specific promoter that organizes specific viral expression. The host transcriptome mechanism due to viral infection gives rise to the fast and discriminating blackout of protein-encoding nuclear transcripts, while the plastid and mitochondrial transcriptomes continued into later stages. Single-cell RNA-seq opens a new path to undo the life cycle of larger viruses and their specific mechanisms [39]. The DNA microarray method identifies 2 transcription processes and 25 specific proteins, and these proteins contain tail sheath protein and a topoisomerase IB by N-terminal sequencing obtained from varphiRSL1 virions [40].

\section{The role of RNA during the host-viral interactions}

The retinoic acid-inducible gene-I-like receptor (RLRs) are key for cytosolic viral determination and for successive initiation of type I interferon secretion. The interferon path increases viral discovery and causes antiviral reflex. The RLRs path contains many of cellular and molecular mechanisms that enable RNA virus recognition and antagonism of RLRs [41]. Varroa mite feeding disrupts viral immunity by the elimination of both virus and immune effectors that stop viral replication. The hemolymph elimination increases in pathogen processes in the presence of feeding Varroa mites [42]. The key host immune system response to viral infection is RNA-dependent protein kinase $\mathrm{R}$ (PKR). The PKR recognizes viral RNA molecules by its $\mathrm{N}$-terminal RNA binding site, increases the phosphorylation of the $\mathrm{C}$-terminal kinase domain, and inhibits viral protein translation through inhibits the effect of eukaryotic initiation factor $2 \alpha$. The virus increases viral non-coding RNA, or protein molecules inhibit PKR's triggering and/or its downstream effect to increase viral replication. The role of viral proteins in inhibiting PKR's effect initiates mechanisms that enable viral proteins to perform this inhibitory effect [43].

In a viral infection, the caspase 3/7 effect induced in the hemocyte homeostasisassociated protein and white spot syndrome virus 134 infections. Moreover, the hemocyte homeostasis-associated protein and spot syndrome virus 134 decreased caspase-induced stimulation of hemocyte homeostasis Casp in vitro. Consequently, hemocyte homeostasisassociated protein and white spot syndrome virus 134 possess a role in the host-pathogen interaction [44]. The communications among viral RNA, nonstructural virus-encoded proteins, and a host factor) in the infection process identifies the above-mentioned factors in the different regions of the host cell. This method is applied in hepatocytes cells [45]. The stimulation of the hepatic interferon is not effective in removing the hepatitis $\mathrm{C}$ virus and is correlated with therapeutic protocol to pegylated (Peg) IFN $\alpha$ treatments. The genetic changes in the IFN $\lambda$ locus to chronic hepatitis $\mathrm{C}$ treatment has decreased, in this locus and other loci ameliorate liver phenotypes such as inflammation, fibrosis progression, and the hepatocellular cancer progress [46]. The viral RNA occurs inside a capsid and surrounds by both the protein layer and lipid envelope. The infection process starts in host epithelial cells and spreads to the peripheral nervous system. In the host, alpha herpesviruses caused chronic infection spread to the central nervous system. The host reaction shows an important role in the viral infection process. Alpha herpesviruses do not contain all the genes necessary for viral replication and spread. The viral replications also need RNA polymerase, ribosomes, dynein, and kinesin for viral replication. Consequently, the infected cell varies from the uninfected cell, where the viral cells contain various components that are necessary to complete the virus life cycle [47]. There is an 
important role for the inflammation in controlling the Middle East respiratory syndrome coronavirus pathogenesis in vivo. The Middle East respiratory syndrome coronavirus is a severe respiratory virus that appears in 2012. Human infections in Saudi Arabia $=38 \%$ case and increasing in its infection due to viral spreading through the air. Consequently, the inflammatory paths and cell groups are very important for protection from coronavirus. By understanding the immune response to coronavirus, scientists can develop effective therapies to inhibit pathogenesis in the nearest future [48].

\subsection{Cell and chemical biology in the viral-host interaction.}

There is an important host factor (CPSF6) that connects with nuclear protein (NP1). The CPSF6 increases the nuclear production of NP1 at the same time. CPSF6 possesses an important role in the progress of capsid mRNAs inside the nucleus. The connection between viral NP1 and host CPSF6 gives the scientist the mechanism that enables viral protein increases viral gene expression and replication as well as antiviral drug discovery [49]. The virus infection causes the spreading of the distraction of transcription termination (DoTT) of RNA polymerase II (RNAPII) in host genes. The HSV-1 protein (ICP27) causes DoTT through connection with the essential mRNA 3' processing factor (CPSF). The ICP27 stimulates mRNA 3' processing for viral and host transcription. So, ICP27 possesses an important role in HSV1-causes viral infection, while CPSF stimulates regulation of transcription end [50].

The RNA binding-deficient stores in nucleoprotein (NP) bodies and the nuclear RNA export factor 1 (NXF1) is necessary for viral protein expression but not for viral RNA synthesis. The NXF1 connects with viral mRNAs but not with viral RNAs. Consequently, the NXF1 promotes the export of viral mRNA:NXF1 complexes from inclusion bodies. This provides a basis for new therapeutic approaches for viruses [51]. The ribosomal proteins (RPs) contain $60 \mathrm{~S}$ subunit control translation of specific mRNAs. The translation process of the RPs in this process controls in the catalyzing peptide bond formation. The ribosomal protein L13 (RPL13) is a regulator of viral translation and infection. Consequently, understanding this process gives rise to the effects of the translation of viral mRNA and thus for the development of viral prevention [52]. The influenza A viruses contain RNA genome include 8 segments. Each RNA segment correlated with the nucleoprotein (NP) and viral RNA polymerase to and from a viral ribonucleoprotein (vRNP) molecule. The formation of viral mRNA is dependent on the host RNA transcription, and for these processes to occur, the vRNPs must pass through the cell nuclear pore complex (NPC) to the nucleus. The influenza A virus NS2 protein is also called the nuclear export protein (NES), and this protein connects with the host cellular nucleoporins during the nuclear export of vRNPs. The human nucleoporin 214 (Nup214) is called an NS2binding protein, and NS2 protein connects with the amino-terminal FG domain of the Nup214 protein. The influenza viral replication was decreased by the Nup214 protein. Consequently, the FG domains of nucleoporins have an important role in the connection of the influenza NS2 protein with host NPC for vRNA spread [53]. The importin- $\alpha 3$ (one of the main NF- $\mathrm{B}$ transporters) is the expressed nuclear factor in the mammalian respiratory tract. The importin$\alpha 3$ promoter effect is controlled by TNF- $\alpha$-induced NF- $\kappa \mathrm{B}$. The increasing of TNF- $\alpha$ increasing pathogenic avian influenza A viruses (HPAIVs) in serious human cases protecting human polymerase signatures (PB2 627K, 701N), which downregulate importin- $\alpha 3$ mRNA expression in the lung cells. The decrease of Importin- $\alpha 3$ is returned by the mutating of the HPAIV polymerase into an avian-type signature (PB2 627E, 701D), which suppresses the high TNF- $\alpha$ levels. The decrease of importin- $\alpha 3$ decreased the NF- $\kappa \mathrm{B}$ antiviral gene expression and 
increased influenza dangerous. Consequently, importin- $\alpha 3$ possesses a role in antiviral immunity in influenza and so importin- $\alpha 3$ in the lung help in the strategy to fight respiratory virus infections [54]. During rotavirus infection, the siRNA facilitates the genetic exhaustion of adenosine triphosphate 5B (ATP5B) or another adenosine triphosphate (ATP) synthase molecules, e.g., ATP5A1 and ATP5O decrease the production of viral new generations without modification of viral RNA amounts and translation. The ATP5B controls the late-stage rotavirus growth in intestinal cells. Consequently, the role of host proteins in rotavirus RNA identifies ATP5B as a novel pro-rotavirus RNA-binding protein that helps scientists to understand virus growth and pathogenesis [55].

The host protein (hnRNP C1/C2) decreases viral RNA translation. The hnRNP C1/C2 connects with stem-loop V in the Internal Ribosome Entry Site' (IRES) and transfers binding protein where this protein controls of viral translation. The hnRNP C1/C2 causes the changing of viral translation to replication. Consequently, the viral RNA translation and replication is controlled by the hnRNP C1/C2 mechanism [56]. The connection of glycyl-tRNA synthetase (GARS) increases the environmental of the initiation area of the IRES in the mRNA binding site of the ribosome that increasing the IRES effect at the step of initiation formation [57].

\subsection{Lipid profiling in the viral-host interaction.}

Potato is a natural host of potato spindle tuber viroid (PSTVd), which causes arresting phenotype and alteration of leaves and tubers. The PSTVd virus replicates in the nucleus and moves in the plant. The host possesses defense, stress, and sugar metabolism correlated genes, which alters expression levels in infection, and the hormone-related genes showed up- or downregulation. Consequently, gibberellin and brassinosteroid paths possess an important role in tuber development upon PSTVd infection [58]. In dengue virus infection, there is an increase in mRNA, myeloid differentiation 2-related lipid recognition protein (ML), and Niemann Picktype $\mathrm{C} 1$ (NPC1) genes. These 3 genes translate lipid-binding proteins, which control the hostviral connection. The RNAi-mediated gene stops the ML and NPC1 genes. In a viral infection, ML and NPC1 increase viral infection by reducing the host immune ability. Consequently, the dengue virus affects the expression of these genes to stimulate viral infection of the mosquito host [59].

\section{Future therapy of coronavirus by using transcriptome}

No vaccines or antiviral drug to avoid or tolerate their infections is available. The coronavirus treatment is only caring. There are many antiviral agents used, e.g., viral proteins of all kinds. Coronavirus is capable of replicating in in vitro studies such as Calu-3 cells and causes lower transcriptomic variations before $12 \mathrm{~h}$ after viral infection. As infection progress, coronavirus causes a significant dysregulation of the host transcriptome greater than the SARS virus. Both viruses induced a similar stimulation of host receptors and the interleukin 17 paths, but coronavirus inhibits the expression of many genes such as type I and II major histocompatibility complex (MHC) genes. This viral effect identifies the ability of the host response to viral infection. There are 207 genes inhibited following coronavirus infection and were used to detect antiviral secretions such as kinase inhibitors and glucocorticoids. Consequently, coronavirus and SARS virus possesses host gene expression reactions that effect on in vivo pathogenesis and therapeutic strategies [60]. In coronavirus infection, the whole blood cytokine investigations increased the cytokine expression in the viral cell infected case. 
The inflammatory gene expression increased after the dysfunction of respiratory function, except the expression in the interleukin-1 (IL1) path. The investigations of CD4 and CD8 expression showed that the pro-inflammatory factors increased with $\mathrm{T}$ cell initiation that leads to prolong the disease or prolong the infection. Consequently, the pro-inflammatory factors such as that IL1 and related pro-inflammatory paths analyzed and used as therapeutic agents for COVID-19 [61].

\section{Conclusions}

Transcriptome refers to all RNA particles occur inside one cell or inside numerous cells in one organ. Coronaviruses are a family of correlated viruses that induce viral infection. In humans, coronaviruses induce respiratory viral infections that may be mild or dangerous. The coronavirus shape is large circular elements that have round tip outbreaks - the virus diameter particles $=120 \mathrm{~nm}$. The RNA viral genome occurs in coronavirus. The coronavirus genome size $=27-34$ kilobases, and this size is the largest RNA genome size. The Life cycle of coronavirus includes viral entry, replication, and release. Coronavirus transmission was done through the connection of its protein with the host cell receptor in a specific process. There are 4 types of coronavirus genus: (1) Alphacoronavirus, (2) Betacoronavirus, (3) Gammacoronavirus, and (4) Deltacoronavirus. Viral molecular mechanism hijacks the host cell protein production mechanism. Coronavirus is capable of replicating in in vitro study and causes lower transcriptomic variations. As infection progress, coronavirus causes a significant dysregulation of the host transcriptome greater than the SARS virus. The future therapy of coronavirus includes the investigations of CD4 and CD8 expression, where these pro-inflammatory factors increased with $\mathrm{T}$ cell initiation that leads to prolonging the infection. Consequently, the proinflammatory factors such as that IL1 and related pro-inflammatory paths analyzed and used as therapeutic agents for COVID-19.

\section{Funding}

This review received no external funding.

\section{Acknowledgments}

This research has no acknowledgment.

\section{Conflicts of Interest}

The author declares no conflict of interest.

\section{References}

1. Kim, D.; Lee, J.Y.; Yang, J.S.; Kim, J.W.; Kim, V.N.; Chang, H. The Architecture of SARS-CoV-2. Transcriptome. Cell 2020, 181, 914-921.e10, http://doi.org/10.1016/j.cell.2020.04.011.

2. Koriem, K.M.M. A lipidomic concept in infectious diseases. Asian Pac J Trop Biomed 2017, 7, 265-274, http://dx.doi.org/10.1016/j.apjtb.2016.12.010.

3. Koriem, K.M.M. Protective effect of natural products and hormones in colon cancer using metabolome: A physiological overview. Asian Pac J Trop Biomed 2017, 7, 957-966, http://dx.doi.org/10.1016/j.apjtb.2017.09.002.

4. Koriem, K.M.M. Proteomic approach in human health and disease: Preventive and cure studies. Asian Pac J Trop Biomed 2018, 8, 226-236, http://doi.org/10.4103/2221-1691.231285.

5. Wang, Z.; Gerstein, M.; Snyder, M. RNA-Seq: a revolutionary tool for transcriptomics. Nature Rev Genetics 2009, 10, 57-63, http://doi.org/10.1038/nrg2484. 
6. Szabo, D. Transcriptomic biomarkers in safety and risk assessment of chemicals. In: Gupta-Biomarkers in Toxicology. Ramesh, G. editors: Oxford, London, United Kingdom, Academic Press. 2014; pp. 1033-1038, http://doi.org/10.1016/B978-0-12-404630-6.00062-2.

7. Kainov, Y.A.; Makeyev, E.V. A transcriptome-wide antitermination mechanism sustaining identity of embryonic stem cells. Nat Commun 2020, 11, http://doi.org/10.1038/s41467-019-14204-z.

8. Chang, L.; Yan, Y.; Wang, L. Coronavirus Disease 2019: Coronaviruses and Blood Safety. Transfus Med Rev 2020, 34, 75-80, http://doi.org/10.1016/j.tmrv.2020.02.003.

9. Fan, Y.; Zhao, K.; Shi, Z.L.; Zhou, P. Bat Coronaviruses in China. Viruses 2019, 11, http://doi.org/10.3390/v1103021.

10. de Groot, R.J.; Baker, S.C.; Baric, R.; Enjuanes, L.; Gorbalenya, A.E.; Holmes, K.V.; Perlman, S.; Poon, L.; Rottier, P.J.; Talbot, P.J.; Woo, P.C.; Ziebuhr, J. Family Coronaviridae. In: International Committee on Taxonomy of Viruses, International Union of Microbiological Societies. Virology Division. King, A.M.; Lefkowitz, E.; Adams, M.J.; Carstens, E.B. (eds.). Ninth Report of the International Committee on Taxonomy of Viruses. Oxford, London, United Kingdom. Elsevier. 2011, pp. 806-828, http://doi.org/10.1016/B978-0-12-384684-6.00068-9.

11. Woo, P.C.; Huang, Y.; Lau, S.K.; Yuen, K.Y. Coronavirus genomics and bioinformatics analysis. Viruses 2010, 2, 1804-1820, http://doi.org/10.3390/v2081803.

12. Cherry, J.; Demmler-Harrison, G.J.; Kaplan, S.L.; Steinbach, W.J.; Hotez, P.J. Feigin and Cherry's Textbook of Pediatric Infectious Diseases. Elsevier Health Sciences 2017, PT6615.

13. Almeida, J.D.; Berry, D.M.; Cunningham, C.H.; Hamre, D.; Hofstad, M.S.; Mallucci, L.; McIntosh, K.; Tyrrell, D.A. Virology: Coronaviruses. Nature 1968, 220, https://doi.org/10.1038/220650b0.

14. Yang, Y.; Peng, F.; Wang, R.; Yange, M.; Guan, K.; Jiang, T.; Xu, G.; Sun, J.; Chang, C. The deadly coronaviruses: The 2003 SARS pandemic and the 2020 novel coronavirus epidemic in China. J Autoimmun 2020, 109, http://doi.org/10.1016/j.jaut.2020.102434.

15. Hasöksüz, M.; Kiliç, S.; Saraç, F. Coronaviruses and SARS-COV-2. Turk J Med Sci 2020, 50, 549-556, https://doi.org/10.3906/sag-2004-127.

16. Definition of Corona by Merriam-Webster. www. Merriam-Webster. Com 2020; March 24.

17. Tyrrell, D.A.; Fielder, M. Cold Wars: The Fight against the common cold. Oxford University Press, London, United Kingdom, 2002; pp. 96.

18. Sturman, L.S.; Holmes, K.V. Lauffer, M.A.; Maramorosch, K. The molecular biology of coronaviruses. $A d v$ Virus Res 1983, 28, 35-112, http://doi.org/10.1016/s0065-3527(08)60721-6.

19. Estola, T. Coronaviruses, a New Group of Animal RNA Viruses. Avian Dis 1970, 14, 330-336, http://doi.org/10.2307/1588476.

20. Fabricant, J. The Early History of Infectious Bronchitis. Avian Dis 1998, 42, 648-650, http://doi.org/10.2307/1592697.

21. Decaro, N. Gammacoronavirus. In: Gammacoronavirus: Coronaviridae. Tidona, C.; Darai, G. (eds.). The Springer Index of Viruses. Springer. 2011, pp. 403-413, http://doi.org/10.1007/978-0-387-95919-1.

22. McIntosh, K. Coronaviruses: A Comparative Review. In: Current Topics in Microbiology and Immunology /Ergebnisse der Mikrobiologie und Immunitätsforschung. Current Topics in Microbiology and Immunology/Ergebnisse der Mikrobiologie und Immunitätsforschung. Arber, W.; Haas, R.; Henle, W.; Hofschneider, P.H.; Jerne, N.K.; Koldovský, P.; Koprowski, H.; Maaløe, O.; Rott, R (eds.). Berlin, Heidelberg: Springer. 1974; pp.87, http://doi.org/10.1007/978-3-642-65775-7.

23. International committee on taxonomy of viruses. (ICTV), 2010.

24. Il était une fois les coronavirus. Réalités Biomédicales. March 27, 2020.

25. Kahn, J. S.; McIntosh, K. History and recent advances in coronavirus discovery. The Pediatric Infect Dis $J$ 2005, 24, S223-S227, http://doi.org/10.1097/01.inf.0000188166.17324.60.

26. Mahase, E. Covid-19: First coronavirus was described in The BMJ in 1965, BMJ 2020, 369, http://doi.org/10.1136/bmj.m1547.

27. Monto, A.S. Coronaviruses. In: Viral infections of humans. viral infections of humans: epidemiology and control. Evans, A.S. Springer US. 1984; pp. 151-165, http://doi.org/10.1007/978-1-4684-4727-9.

28. Kendall, E.J.; Bynoe, M.L.; Tyrrell, D.A. Virus isolations from common colds occurring in a residential school. Br Med J 1962, 2, 82-86, http://doi.org/10.1136/bmj.2.5297.82.

29. Richmond, C. David Tyrrell. BMJ: Br Med J 2005, 330, http://doi.org/10.1136/bmj.330.7505.1451.

30. Obituary Notices: Malcom Byone. Br Med J 1969, 2, 827-829, http://doi.org/10.1136/bmj.2.5660.827.

31. Giaimo, C. The Spiky Blob Seen Around the World. $N$ Y Times 2020.

32. International committee on taxonomy of viruses (ICTV). 2018.

33. International committee on taxonomy of viruses (ICTV). 2020.

34. Reid, D.W.; Campos, R.K.; Child, J.R.; Zheng, T.; Chan, K.W.K.; Bradrick, S.S.; Vasudevan, S.G.; GarciaBlanco, M.A.; Nicchitta, C.V. Dengue Virus Selectively Annexes Endoplasmic Reticulum-Associated Translation Machinery as a Strategy for Co-opting Host Cell Protein Synthesis. J Virol 2018, 92, e0176617.

35. Rato, S.; Golumbeanu, M.; Telenti, A.; Ciuffi, A.; Reid, D.W.; Campos, R.K.; Child, J.R.; Zheng, T.; Chan, K.W.K.; Bradrick, S.S.; Vasudevan, S.G.; Garcia-Blanco, M.A.; Nicchitta, C.V.; Ren, L.; Ding, S.; Song, 
Y.; Li, B.; Ramanathan, M.; Co, J.; Amieva, M.R.; Khavari, P.A.; Greenberg, H.B. Profiling of rotavirus 3'UTR-binding proteins reveals the ATP synthase subunit ATP5B as a host factor that supports late-stage virus replication. J Biol Chem 2019, 294, 5993-6006, http://doi.org/10.1074/jbc.RA118.006004.

36. Levenson, E.A.; Martens, C.; Kanakabandi, K.; Turner, C.V.; Virtaneva, K.; Paneru, M.; Ricklefs, S.; Sosnovtsev, S.V.; Johnson, J.A.; Porcella, S.F.; Green, K.Y.; Ong, E.Z.; Chan, Y.F.Z.; Leong, W.Y.; Lee, N.M.Y.; Kalimuddin, S.; Haja Mohideen, S.M.; Chan, K.S.; Tan, A.T.; Bertoletti, A.; Ooi, E.E.; Low, J.G.H. A Dynamic Immune Response Shapes COVID-19 Progression. Cell Host Microbe 2020, 27, 879-882.e2, http://doi.org/10.1016/j.chom.2020.03.021.

37. Ramasubramanyan, S.; Osborn, K.; Al-Mohammad, R.; Naranjo Perez-Fernandez, I.B.; Zuo, J.; Balan, N.; Godfrey, A.; Patel, H.; Peters, G.; Rowe, M.; Jenner, R.G.; Sinclair, A.J. Epstein-Barr virus transcription factor Zta acts through distal regulatory elements to directly control cellular gene expression. Nucleic Acids Res 2015, 43, 3563-3577, http://doi.org/10.1093/nar/gkv212.

38. Chang, S.T.; Thomas, M.J.; Sova, P.; Green, R.R.; Palermo, R.E.; Katze, M.G. Next-generation sequencing of small RNAs from HIV-infected cells identifies phased microrna expression patterns and candidate novel microRNAs differentially expressed upon infection. mBio 2013, 4, e00549-12, http://doi.org/10.1128/mBio.00549-12.

39. Ku, C.; Sheyn, U.; Sebé-Pedrós, A.; Ben-Dor, S.; Schatz, D.; Tanay, A.; Rosenwasser, S.; Vardi, A. A singlecell view on alga-virus interactions reveals sequential transcriptional programs and infection states. Sci Adv 2020, 6, http://doi.org/10.1126/sciadv.aba4137.

40. Yamada, T.; Satoh, S.; Ishikawa, H.; Fujiwara, A.; Kawasaki, T.; Fujie, M.; Ogata, H. A jumbo phage infecting the phytopathogen Ralstonia solanacearum defines a new lineage of the Myoviridae family. Virology 2010, 398, 135-147, http://doi.org/10.1016/j.virol.2009.11.043.

41. Leung, D.W. Mechanisms of Non-segmented Negative Sense RNA Viral Antagonism of Host RIG-I-Like Receptors. J Mol Biol 2019, 431, 4281-4289, http://doi.org/10.1016/j.jmb.2019.06.002.

42. Annoscia, D.; Brown, S.P.; Di Prisco, G.; De Paoli, E.; Del Fabbro, S.; Frizzera, D.; Zanni, V.; Galbraith, D.A.; Caprio, E.; Grozinger, C.M.; Pennacchio, F.; Nazzi, F. Haemolymph removal by Varroa mite destabilizes the dynamical interaction between immune effectors and virus in bees, as predicted by Volterra's model. Proc Biol Sci 2019, 286, http://doi.org/10.1098/rspb.2019.0331.

43. Dzananovic, E.; McKenna, S.A.; Patel, T.R. Viral proteins targeting host protein kinase R to evade an innate immune response: a mini review. Biotechnol Genet Eng Rev 2018, 34, 33-59, http://doi.org/10.1080/02648725.2018.1467151.

44. Apitanyasai, K.; Amparyup, P.; Charoensapsri, W.; Sangsuriya, P.; Tassanakajon, A. Shrimp hemocyte homeostasis-associated protein (PmHHAP) interacts with WSSV134 to control apoptosis in white spot syndrome virus infection. Fish Shellfish Immunol 2018, 76, 174-182, http://doi.org/10.1016/j.fsi.2018.01.043.

45. Knodel, M.M.; Reiter, S.; Targett-Adams, P.; Grillo, A.; Herrmann, E.; Wittum, G. 3D Spatially resolved models of the intracellular dynamics of the hepatitis C genome replication cycle. Viruses 2017, 9, http://doi.org/10.3390/v9100282.

46. Heim, M.H.; Bochud, P.Y.; George, J. Host-hepatitis C viral interactions: The role of genetics. J Hepatol 2016, 65, S22-S32, http://doi.org/10.1016/j.jhep.2016.07.037.

47. Engel, E.A.; Song, R.; Koyuncu, O.O.; Enquist, L.W. Investigating the biology of alpha herpesviruses with MS-based proteomics. Proteomics 2015, 15, 1943-1956, http://doi.org/10.1002/pmic.201400604.

48. Kyratsous, C.A.; Frieman, M.B. CD8+ T Cells and Macrophages Regulate Pathogenesis in a Mouse Model of Middle East Respiratory Syndrome. J Virol 2016, 91, e01825-16, http://doi.org/10.1128/JVI.01825-16.

49. Wang, X.; Xu, P.; Cheng, F.; Li, Y.; Wang, Z.; Hao, S.; Wang, J.; Ning, K.; Ganaie, S.S.; Engelhardt, J.F.; Yan, Z.; Qiu, J. Cellular Cleavage and Polyadenylation Specificity Factor 6 (CPSF6) Mediates Nuclear Import of Human Bocavirus 1 NP1 Protein and Modulates Viral Capsid Protein Expression. J Virol 2020, 94, e01444-19, http://doi.org/10.1128/JVI.01444-19.

50. Wang, X.; Hennig, T.; Whisnant, A. W.; Erhard, F.; Prusty, B.K.; Friedel, C.C.; Forouzmand, E.; Hu, W.; Erber, L.; Chen, Y.; Sandri-Goldin, R.M.; Dölken, L.; Shi, Y. Herpes simplex virus blocks host transcription termination via the bimodal activities of ICP27. Nat Commun 2020, 11, http://doi.org/10.1038/s41467-01914109-x.

51. Wendt, L.; Brandt, J.; Bodmer, B.S.; Reiche, S.; Schmidt, M.L.; Traeger, S.; Hoenen, T. The Ebola Virus Nucleoprotein Recruits the Nuclear RNA Export Factor NXF1 into Inclusion Bodies to Facilitate Viral Protein Expression. Cells 2020, 9, http://doi.org/10.3390/cells9010187.

52. Han, S.; Sun, S.; Li, P.; Liu, Q.; Zhang, Z.; Dong, H.; Sun, M.; Wu, W.; Wang, X.; Guo, H. Ribosomal Protein L13 Promotes IRES-Driven Translation of Foot-and-Mouth Disease Virus in a Helicase DDX3Dependent Manner. J Virol 2020, 94, e01679-19, http://doi.org/10.1128/JVI.01679-19.

53. Şenbaş Akyazi, B.; Pirinçal, A.; Kawaguchi, A.; Nagata, K.; Turan, K. Interaction of influenza A virus NS2/NEP protein with the amino-terminal part of Nup214. Turk J Biol 2020, 44, 82-92.

54. Thiele, S.; Stanelle-Bertram, S.; Beck, S.; Kouassi, N.M.; Zickler, M.; Müller, M.; Tuku, B.; Resa-Infante, P.; van Riel, D.; Alawi, M.; Günther, T.; Rother, F.; Hügel, S.; Reimering, S.; McHardy, A.; Grundhoff, A.; Brune, W.; Osterhaus, A.; Bader, M.; Hartmann, E.; Gabriel, G. Cellular Importin- $\alpha 3$ Expression Dynamics 
in the Lung Regulate Antiviral Response Pathways against Influenza A Virus Infection. Cell Rep 2020, 31 , http://doi.org/10.1016/j.celrep.2020.107549.

55. Ren, L.; Ding, S.; Song, Y.; Li, B.; Ramanathan, M.; Co, J.; Amieva, M.R.; Khavari, P.A.; Greenberg, H.B. Profiling of rotavirus 3'UTR-binding proteins reveals the ATP synthase subunit ATP5B as a host factor that supports late-stage virus replication. $J$ Biol Chem 2019, 294, 5993-6006, http://doi.org/10.1074/jbc.RA118.006004.

56. Dave, P.; George, B.; Balakrishnan, S.; Sharma, D.K.; Raheja, H.; Dixit, N.M.; Das, S. Strand-specific affinity of host factor hnRNP C1/C2 guides positive to negative-strand ratio in Coxsackievirus B3 infection. RNA Biol 2019, 16, 1286-1299, http://doi.org/10.1080/15476286.2019.1629208.

57. Andreev, D.E.; Hirnet, J.; Terenin, I.M.; Dmitriev, S.E.; Niepmann, M.; Shatsky, I.N. Glycyl-tRNA synthetase specifically binds to the poliovirus IRES to activate translation initiation. Nucleic Acids Res 2012, 40, 5602-14, http://doi.org/10.1093/nar/gks182.

58. Katsarou, K.; Wu, Y.; Zhang, R.; Bonar, N.; Morris, J.; Hedley, P.E.; Bryan, G.J.; Kalantidis, K.; Hornyik, C. Insight on Genes Affecting Tuber Development in Potato upon Potato spindle tuber viroid (PSTVd) Infection. PLoS One 2016, 11, http://doi.org/10.1371/journal.pone.0150711.

59. Jupatanakul, N.; Sim, S.; Dimopoulos, G. Aedes aegypti ML and Niemann-Pick type C family members are agonists of dengue virus infection. Dev Comp Immunol 2014, 43, 1-9, http://doi.org/10.1016/j.dci.2013.10.002.

60. Josset, L.; Menachery, V.D.; Gralinski, L.E.; Agnihothram, S.; Sova, P.; Carter, V.S.; Yount, B.L.; Graham, R.L.; Baric, R.S.; Katze, M.G. Cell host response to infection with novel human coronavirus EMC predicts potential antivirals and important differences with SARS coronavirus. mBio 2013, 4, http://doi.org/10.1128/mBio.00165-13.

61. Ong, E.Z.; Chan, Y.F.Z.; Leong, W.Y.; Lee, N.M.Y.; Kalimuddin, S.; Haja, Mohideen, S.M.; Chan, K.S.; Tan, A.T.; Bertoletti, A.; Ooi, E.E.; Low, J.G.H. A Dynamic Immune Response Shapes COVID-19 Progression. Cell Host Microbe 2020, 27, 879-882.e2, http://doi.org/10.1016/j.chom.2020.03.021. 